\title{
Life and death in a medieval atmosphere
}

\author{
Christoph Borner ${ }^{1}$, Laurent Monney ${ }^{1}$, Reynald Olivier ${ }^{1}$, Thierry Rossé ${ }^{1}$, Jürg Häcki ${ }^{1}$ and Sébastien Conus ${ }^{1}$ \\ ${ }^{1}$ Institute of Biochemistry, University of Fribourg, Rue du Musée 5, CH-1700, Fribourg, Switzerland, e-mail: christoph.borner@unifr.ch
}

1st International Conference on 'Life and Death of a Cell'

3rd National Meeting of the Swiss Tissue Culture Society (STCS),

Fribourg, Switzerland, September 17-18, 1998

\begin{abstract}
Abbreviations: Abbreviations: TNF $\alpha$, tumornecrosis factor $\alpha$; DED, death effector domain; CARD, caspase recruiting domain; FADD, Fas-associated death domain; RIP, receptor interacting protein; RAIDD, RIP-associated Ich-1/CED-3 homologous protein with a death domain; CARDIAK, CARD-containing interleukin- $1 \beta$ converting enzyme associated kinase; TRAF, TNF receptor associated factor; ASK, apoptosis signal-regulating kinase 1; JNK, jun $\mathrm{N}$ terminal kinase; IAP, inhibitor of apoptosis proteins; CAD, caspase activated DNase; ICAD, inhibitor of caspase activated DNase; NLS, nuclear localization signal; Dox, doxorubicin; Bet A, betulinic acid; AIF, apoptosis inducing factor; IGF-1, insulin-like growth factor-1; CREF2, cytochrome crelease enhancing factor-2; Apaf-1, apoptotic protease activating factor $1 ; \mathrm{PT}$, permeability transition pore; ROS, reactive oxygen species; CsA, cyclosporine $A$; NGF, nerve growth factor; $\mathrm{ER}$, endoplasmic reticulum; $\mathrm{BH}, \mathrm{Bcl}-2$ homology domain; EMS, ethylmethane sulfonate; GAP-43, neuromodulin; NT-3, neurotrophin-3
\end{abstract}

At the site where 517-years-ago people fought for their liberation from the Duke of Savoyen to become a sovereign state within helvetic Switzerland, 300 researchers from 21 countries recently gathered to fight for the 'life and death of a cell'. A cowbell, representing the rural aspect of the site, announced the beginnings and endings of each little fight. These fights were however more peaceful and cooperative than the ancient ones as people were eager to exchange new ideas and data on apoptosis research at every possible occasion. By the end of the meeting, it was clear that although new pieces have been added to the jigsaw puzzle of apoptosis, we are far from understanding the complexity by which a cell fights for or against its death fate.

The present report highlights some of the new pieces that have been fitted into three intertwined paths for apoptosis: (i) the receptor-activated, proximal path used by CD95, TNF $\alpha$ and related factors and some anticancer drugs (Figure 1, blue), (ii) the mitochondrial path used by many toxic agents, irradiation, ceramide and cytokine removal (Figure 1, green) and (iii) a newer, caspaseindependent path seen in sperms, erythrocytes and during Wallerian degeneration (Figure 1, brown). Moreover, evidence is presented that the endoplasmic reticulum is slowly resurrecting in apoptosis research after being almost buried by the dominance of mitochondria (Figure 1, red). Finally, it seems that apoptosis in the nematode $C$. elegans is getting more complex than previously thought.

\section{Death receptors signaling, caspase activation and nuclear events}

V. Dixit (San Francisco, USA) summarized the CD95/TNF receptor-activated path that activates caspases by proximity ${ }^{1}$ (Figure 1, blue). In this path, a receptor-bound adapter molecule binds to the large prodomain of a slightly active procaspase via special protein motifs called death effector (DED) or caspase recruitment (CARD) domains. These DEDDED or CARD-CARD interactions approximate the procaspase such that it autoprocesses to the active protease. ${ }^{2}$ While the adapter FADD acts as aggregator and autoactivator of procaspase-8, RAIDD may perform the same function on procaspase-2. M. Thome (Lausanne, Switzerland) presented yet another CARD-containing adaptor molecule, called CARDIAK. This protein is a RIP-like serine/threonine protein kinase that binds via CARD-CARD interactions to the proinflammatory procaspase-1 to autoactivate the protease. ${ }^{3}$ CARDIAK also binds to the TNF receptor associated factors TRAF-1 and TRAF-2 and transmits signals to the JNK (jun kinase) and the anti-apoptotic NF- $\kappa \mathrm{B}^{3}{ }^{3}$

R. Khosravi-Far (Cambridge, USA) discussed a second, FADD-independent death signaling pathway triggered by CD95. This path involves the molecule Daxx which binds to CD95 and then triggers caspase activation and apoptosis via the activation of ASK (apoptosis signal-regulating kinase 1) and $\mathrm{JNK}^{4,5}$ (Figure 1, blue). Interestingly, the Daxx path, unlike the FADD path, is sensitive to Bcl-2 explaining why $\mathrm{Bcl}-2$ can sometimes protect cells from CD95-induced apoptosis.

CrmA of cowpox virus blocks death-receptor activated apoptosis because it preferentially inhibits caspase- 1 and caspase- $8 .{ }^{6}$ To extend the specificity of CrmA to other caspases the group of D. Vaux (Melbourne, Australia) generated CrmA variants that had the pseudosubstrate region LVAD replaced by the preferred substrate peptides of various classes of caspases. Surprisingly, a crmA-DEVD variant that should be a general death antagonist because it targets the execution caspases-3/-7 was inefficient in blocking Fas- and dexamethasone-induced apoptosis. It turned out that the inhibitor is cleaved after occupying the catalytic site of the caspases. By contrast, a crmA-DQMD variant is not degraded and thus a potent inhibitor of caspase-3 (Figure 1, pink). D. Vaux also summarized the evolutionary origin and function of the inhibitor of apoptosis proteins (IAPS). Some of these inhibitors directly bind and 
block certain caspases ${ }^{7}$ and a zinc binding fold called BIR is crucial for their inhibitory action. ${ }^{8}$ Strikingly, yeast strains encode BIR-containing IAP family proteins although no caspases are made by these cells. Thus, IAPs represent the first anti-cell death family of proteins found in single celled organisms that do not necessarily act on caspases.

Downstream of most death pathways is the degradation of genomic DNA into nucleosome-sized fragments. A crucial mediator of this response is CAD, a DNase residing inactive in the cytoplasm bound to its inhibitor ICAD and entering the nucleus after its inhibitor is cleaved by caspases $^{9,10}$ (Figure 1, pink). S. Nagata (Osaka, Japan) showed that nuclear translocation of a GFP-CAD version depends on the presence of ICAD, active caspase- 3 and a nuclear localization signal (NLS) at the N-terminus of CAD. $\mathrm{He}$ also revealed that apoptosis can occur in the absence of DNA laddering as overexpression of ICAD blocked CAD and subsequent DNA fragmentation but not cell death induced by staurosporine.

An alternative way to trigger nuclear degradation during apoptosis may be by a direct nuclear action of caspases. The group of A. Porter (Singapore) uncovered a NLS sequence in the pro-domain of pro-caspase- 1 that drives the zymogen and heterologous cytoplasmic proteins into the nucleus. ${ }^{11}$ Surprisingly, the prodomain itself is capable of inducing apoptosis when present in nuclei. The mechanism of such an action is yet unknown but it may involve the binding of pro-apoptotic nuclear proteins via CARD-CARD interactions.

\section{Crosstalk between the receptor-activated pathway and mitochondria}

In certain cells activated CD95 inefficiently recruits FADD/ caspase-8 and uses a mitochondrial, cytochrome c/Apaf-1/ caspase-9 dependent pathway to enhance caspase-3 activation and subsequent DNA degradation ${ }^{12}$ (Figure 1, green). As presented by K.-M. Debatin (UIm, Germany), such a death receptor/mitochondria crosstalk is also seen with anticancer drugs but the molecular ordering of the signaling components varies with the drug. While doxorubicin (Dox) triggers the CD95L/CD95 system leading to caspase-8 activation and a $\mathrm{Bcl}-2 / \mathrm{Bcl}-\mathrm{x}_{\mathrm{L}}$ blockable loss in mitochondrial $\Delta \Psi_{\mathrm{m}}$, betulinic acid (Bet A) directly acts on mitochondria, triggers a Bcl-2/Bcl- $\mathrm{x}_{\mathrm{L}}$ blockable loss in mitochondrial $\Delta \Psi_{\mathrm{m}}$ but only then activates caspase- $8^{13}$ (Figure 1, green/blue).

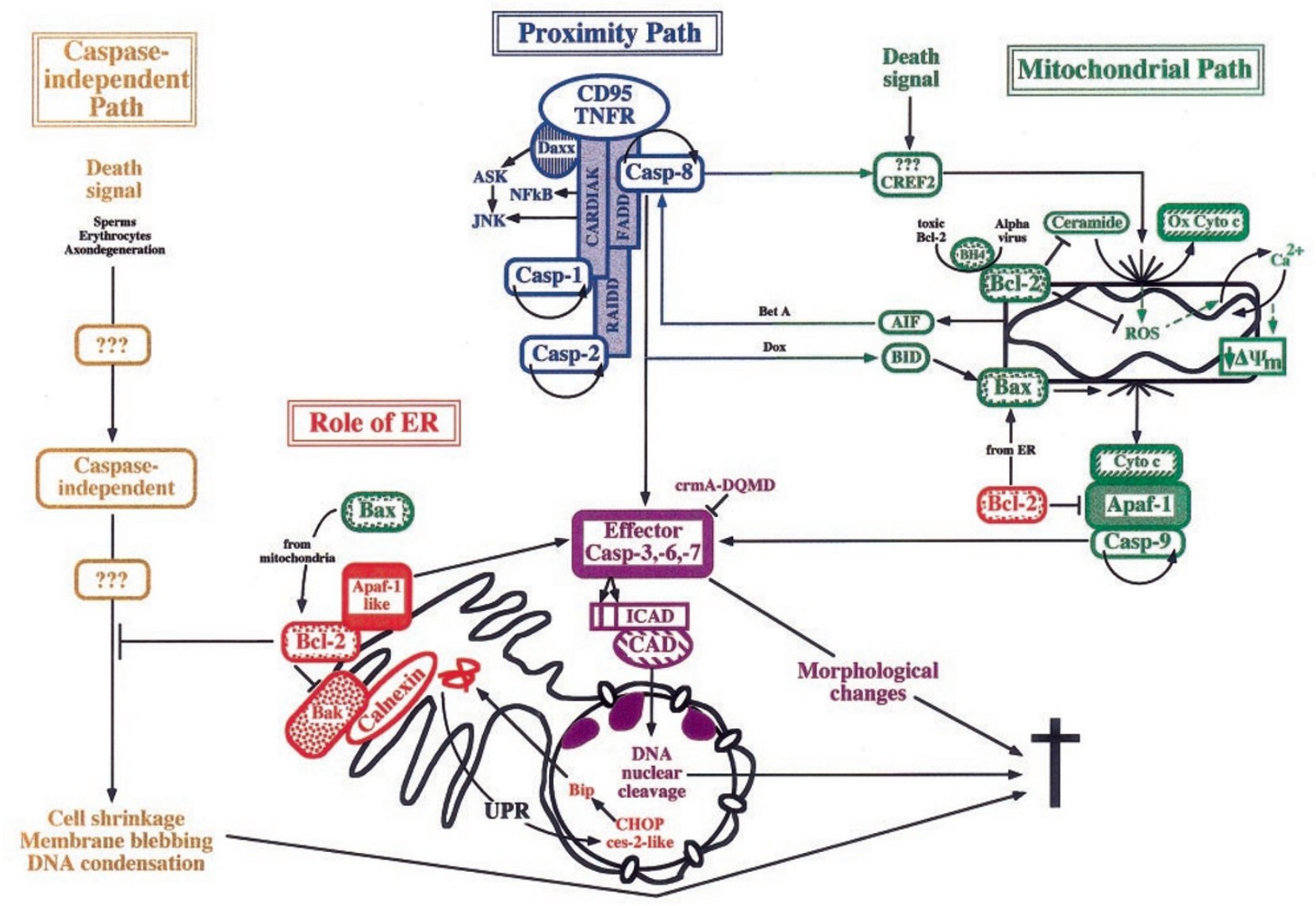

Figure 1 The emerging jigsaw puzzle of apoptosis signaling. The figure represents a summary of the new pieces that have been added to the jigsaw puzzle of apoptosis signaling. This puzzle consists of at least three signaling pathways, the proximal (blue), the mitochondrial (green) and the caspase-independent (brown) paths which crosstalk to each other to determine the 'life or death of the cell'. The putative role of the ER in apoptosis regulation is also depicted (red). For details, see text. 
The mitochondrial trigger of caspase- 8 activation in the latter case appears to be apoptosis inducing factor (AIF) rather than cytochrome c.

Another cross-talk between the CD95 pathway and mitochondria was presented by G. Evan (London, UK). He showed that $c-m y c$, which sensitizes cells to apoptosis when nutrients are scarce, cooperates with the CD95 signaling to effectively induce apoptosis. ${ }^{14}$ The co-operation involves mitochondria as c-myc triggers cytochrome $\mathrm{c}$ release in a IGF-1 inhibitable manner and microinjection of cytochrome c accelerates CD95-induced apoptosis. However, cytochrome $c$ alone cannot induce caspase activation and apoptosis but requires a FADD-mediated pathway indicating that CD95 and c-myc signals converge at a step after cytochrome release but before caspase activation. G. Evan also presented exciting new data regarding the oncogenic versus apoptotic potential of c-myc in vivo. By generating mice harboring a switchable Myc protein in specific tissues, he showed that while c-myc triggered proliferation followed by apoptosis in pancreatic $\beta$-cell because survival factors were limiting, it induced dysplasia in the skin because keratinocytes appeared to be protected from apoptosis by survival signals.

\section{The apoptotic role of mitochondria}

Although it is yet unclear whether the release of cytochrome $c$ and the fall in the membrane potential are coupled, they are the most widely discussed mitochondrial effector events occurring in response to various non-receptor-activated types of apoptotic stimuli. ${ }^{15}$ At least for cytochrome $c$ the downstream path is deciphered and involves the oligomerization of the CED-4 homolog Apaf-1 which in turn triggers oligomerization and autoactivation of pro-caspase- 9 and subsequent activation of the effector caspases-3, -6 and $-7^{16}$ (Figure 1, green). D. Newmeyer (La Jolla, USA) presented convincing evidence that the loss of the mitochondrial membrane potential $\left(\Delta \Psi_{\mathrm{m}}\right)$ in response to UV-light occurred downstream of caspases, some hours after cytochrome c release. Similarly, D. Grubb (Clayton, Australia) found that cytochrome $c$ release in response to the anti-tumor/viral agent didemnin B is an early event occurring independently and prior to a loss of $\Delta \Psi_{\mathrm{m}}$. These data are consistent with those reported from Apaf-1 and caspase-9 knock out mice where cytochrome $\mathrm{c}$ was still released in response to apoptotic stimuli but no further changes in $\Delta \Psi_{\mathrm{m}}$ occurred. ${ }^{17,18} \mathrm{D}$. Newmeyer also showed that other intermembrane space mitochondrial proteins such as adenylate kinase and sulfite oxidase were co-released with cytochrome c prior to caspase-9/-3 activation. Based on electron microscopy and sucrose experiments, the release of these proteins is not due to mitochondrial swelling but to a yet uncharacterized increase in the permeability of the outer mitochondrial membrane. On the search for factors that trigger cytochrome $c$ release, the group of D. Newmeyer purified CREF2. This factor is different from the recently published cytochrome $\mathrm{C}$ releasing factor BID $^{19,20}$ but, like BID, requires caspase- 8 for its activation (Figure 1, green).

A study presented by C. Richter (Zürich, Switzerland) also puts the fall in $\Delta \Psi_{\mathrm{m}}$ downstream of cytochrome $\mathrm{C}$ release and even questions the necessity of a permeability transition pore (PT) for these two processes. In an impressive textbook lecture, he linked three widely discussed mediators of apoptosis to mitochondria; ceramide, calcium and reactive oxygen species (ROS) (Figure 1, green). It has recently been shown that ceramide produced by various apoptotic agents accumulates on mitochondria where it leads to cytochrome $\mathrm{c}$ release. ${ }^{21} \mathrm{C}$. Richter now shows that ceramide can directly bind to and release cytochrome c provided that the latter is oxidized. As a consequence, electron flow towards cytochrome c oxidase is interrupted, the respiratory chain members upstream of cytochrome $\mathrm{c}$ are more reduced and therefore readily form superoxide radicals (ROS). ROS help oxidized cytochrome $c$ to be released by ceramide but also augment $\mathrm{Ca}^{2+}$ release from mitochondria followed by re-uptake $\left(\mathrm{Ca}^{2+}\right.$ 'cycling'). Excessive $\mathrm{Ca}^{2+}$ cycling results in an increased energy demand and a dramatic fall of $\Delta \Psi_{\mathrm{m}}$. Consequently, the cell is deprived of its fuel for $\mathrm{Ca}^{2+}$-sequestering ATPases, less $\mathrm{Ca}^{2+}$ is taken up by organelles and the cytosolic $\mathrm{Ca}^{2+}$ content rises to apoptosis inducing levels. ${ }^{22}$ Thus, C. Richter proposes that 'PT' simply reflects increased $\mathrm{Ca}^{2+}$ cycling leading to energy deprivation, a loss in $\mathrm{Ca}^{2+}$ uptake and the fall in $\Delta \Psi_{\mathrm{m}}$. Since $\mathrm{Ca}^{2+}$ release from mitochondria is cyclosporine A (CsA) sensitive, this looks similar to blocking $\mathrm{PT}^{22} \mathrm{Bcl}-2$ abrogates the action of ceramide ${ }^{23,24}$ and acts as antioxidant, ${ }^{25,26}$ thus preventing enhanced $\mathrm{Ca}^{2+}$ cycling and the fall in $\Delta \Psi_{\mathrm{m}}$ (Figure 1, green).

Another example where the loss of $\Delta \Psi_{\mathrm{m}}$ and cytochrome $c$ release occurs independently of $P T$ is when mitochondria are treated with recombinant Bax as shown by J.-C. Martinou $^{44}$ (Serono, Geneva). Moreover, his group discovered that cytochrome $c$ release is reversible in neurons deprived of NGF and that BID is a potential trigger of the apoptotic changes of mitochondria. When full length, recombinant BID is added to isolated mitochondria, it translocates to the mitochondrial membrane where it interacts with Bax (Figure 1, green). This interaction provokes a conformational change in Bax because a previously hidden $\mathrm{N}$-terminal epitope now becomes available to a Bax antibody. Mutagenesis analysis showed that the $\mathrm{BH} 3$ region of $\mathrm{BID}$ is responsible for mitochondrial translocation, interaction and structural alteration of Bax.

K. D'Herde (Gent, Belgium) provided a possible answer to the longstanding question of how ATP production necessary for apoptosis execution can be maintained after cytochrome $c$ release. Using a diaminobenzidine oxidation reaction to localize cytochrome $\mathrm{c}$ at the ultrastructural level in mitochondria of normal and apoptotic ovary granulosa cells, she shows that although most of the cytochrome staining is reduced after nuclear manifestation of apoptosis, several mitochondria preserve cytochrome c function and therefore the capacity to synthesize ATP.

\section{How do Bcl-2 family members act? 'Resurrection' of the ER in apoptosis research}

Several mechanisms of action have been proposed for $\mathrm{Bcl}-2$ family members. Analogous to nematodes where CED-9, CED-4 and CED-3 form a ternary complex such that CED-9 prevents the adaptor CED-4 from activating the caspase 
CED-3, direct interactions occur in mammalian systems that allow $\mathrm{BCl}-\mathrm{x}_{\mathrm{L}}$ to bind the CED-4 homolog Apaf-1 and prevent it from activating pro-caspase-9. ${ }^{27,28}$ Unfortunately, we have so far been unable to detect any interaction between Bcl-2 and Apaf-1 (own observation) indicating that the physiological partner of Bcl-2 may be an Apaf-1 homolog rather than Apaf-1 itself (Figure 1, red). Moreover, we still do not know exactly where $\mathrm{Bcl}-2$ and other family members act within the cell. Although mitochondria are an attractive site, $\mathrm{Bcl}-2$ and $\mathrm{Bcl}-\mathrm{x}_{\mathrm{L}}$ also reside on the $\mathrm{ER} /$ nuclear membrane ${ }^{29}$ and adenoviral E1B-19K, a potent survival factor exhibiting limited sequence homology to $\mathrm{Bcl}-2$, has recently been shown to attract CED-4 to the ER membrane. ${ }^{30}$

R. Brown (Stevenage, UK) lends further support to a possible role of the ER in apoptosis induction. He shows that the proapoptotic Bcl-2 family member Bak binds to the cytoplasmic face of the ER-resident chaperone protein calnexin and requires this protein for its lethal effect in yeast $^{45}$ (Figure 1, red). Although the impact of Bak on calnexin is yet unclear, it may interfere with its normal function to retain incorrectly or incompletely folded ER proteins. $^{31}$ Unfolded proteins stimulate an unfolded protein response (UPR) pathway towards the nucleus to increase the expression of ER chaperones like Bip which then assure proper ER protein folding and/or degradation ${ }^{32}$ (Figure 1, red). The group of $\mathrm{R}$. Brown isolated two transcription factors, called CREB2/ATF4 and CHOP/ GADD53 that are transiently induced by tunicamycin (a drug provoking misfolded proteins in the ER). Strikingly, both proteins bind to ces-2, a PAR family transcription factor required for programmed cell death in C.elegans. ${ }^{33}$ As overexpression of ces-2 or its mammalian homolog E2A-HLF ${ }^{34}$ inhibit rather than provoke cell death in mammals, their interactions with CREB2 and CHOP may protect a cell from death induced by misfolded ER proteins. Consistently, R. Brown shows that cells from $\mathrm{CHOP}-/-$ mice are more sensitive to tunicamycin induced apoptosis.

C. Borner (Fribourg, Switzerland) presented further insights into the mechanisms that determine subcellular sites and pro- versus antiapoptotic activities of Bcl-2 family members. His group found that $\mathrm{Bcl}-2$ interferes with Baxinduced apoptosis via two mechanisms; it is attracted to Bax on mitochondria where it cannot block cytochrome $c$ release but downstream events such as caspase activation $^{35}$ or it moves Bax away from mitochondria to the ER/ nuclear membrane and thereby prevents Bax from releasing cytochrome $c$ (Figure 1, red/green). The latter suggests a physiological function of $\mathrm{Bcl}-2$ on the $\mathrm{ER} /$ nuclear membrane. Moreover, by generating $\mathrm{Bcl}-2 / \mathrm{Bax}$ chimeric proteins that have their $\mathrm{BH}$ domains and/or $\mathrm{C}$ termini exchanged, $\mathrm{C}$. Borner showed that a combined action of $\mathrm{BH} 4, \mathrm{BH} 1$ and $\mathrm{BH} 2$ of $\mathrm{Bcl}-2$ is required to convert Bax into a survival factor. As Bcl-2, this survival factor is now mainly associated with the ER. By contrast, single mutations or deletions of $\mathrm{BH} 4, \mathrm{BH} 1$ and/or $\mathrm{BH} 2$ domains of $\mathrm{Bcl}-2$ can convert $\mathrm{Bcl}-2$ into a cytotoxic factor that is mainly associated with mitochondria. These data indicate that Bcl2 has an inherent cytotoxic activity and that the $\mathrm{BH} 4, \mathrm{BH} 1$ and $\mathrm{BH} 2$ domains serve to protect $\mathrm{Bcl}-2$ from its proapoptotic action and to target it to the ER.
D. Grandgirard (Berne, Switzerland) presented evidence that the conversion of $\mathrm{Bcl}-2$ into a cytotoxic factor may occur under physiological conditions. He showed that alphaviruses kill Bcl-2 overexpressing cells by provoking the removal of the $\mathrm{BH} 4$ domain of $\mathrm{Bcl}-2$ via a caspasemediated proteolytic cleavage, thus converting $\mathrm{Bcl}-2$ into a putatively cytotoxic device ${ }^{36}$ (Figure 1, green). The mechanism by which viruses activate host cell caspases is yet unknown but it may involve virus-encoded proteases such as the capsid protein or the nsP2 protease.

Another way to degrade $\mathrm{Bcl}-2$ is to target the protein to the ubiquitin-dependent degradation pathway. S. Dimmeler (Frankfurt, Germany) showed that this mechanism of $\mathrm{Bcl}-2$ degradation occurs in response to $\mathrm{TNF} \alpha$ providing yet another explanation why TNF $\alpha$-induced apoptosis is only partially blocked by $\mathrm{Bcl}-2$.

Downregulating the expression of $\mathrm{Bcl}-2$ may be an attractive strategy to sensitize high Bcl-2 expressing tumors such as melanomas for apoptosis. The group of B. Jansen (Vienna, Austria) used antisense oligonucleotides directed against $\mathrm{Bcl}-2$ to decrease tumor weight and improve chemosensitivity of human melanoma xenotransplanted into SCID mice. ${ }^{37}$

\section{Caspase-independent apoptosis: is it real and physiological?}

Studies in yeast (lacking caspases) and with the broad spectrum caspase inhibitor Z-VAD-fmk in mammalian cells have revealed an apparently caspase-independent mode of apoptosis that still involves cell shrinkage, DNA condensation and membrane blebbing but usually no DNA fragmentation $^{15,38}$ (Figure 1, brown). The molecular characterization of this type of death has been hampered due to the lack of proper physiological systems and the use of chemical inhibitors and protein overexpression systems which may either not inhibit all caspases or generate artificial conditions. The best physiological examples of caspase-independent deaths stem from studies of Dictyostelium differentiation ${ }^{39}$ and, more recently, germ cell death in C.elegans (see below). M. Raff (London, UK) further challenged this issue by studying caspase-independent apoptosis in cells that have transcriptionally inactive nuclei. Although still using Z-VAD-fmk inhibition and caspase activation assays, he showed that spontaneous apoptosis in sperms and staurosporine/cycloheximide-triggered apoptosis in chicken erythrocytes did not involve caspases. ${ }^{40}$ Moreover, while a bcl-2 transgene or ZVAD-fmk could protect the cell body of retinal ganglion cells from apoptosis when the axon is cut, neither agent protected the isolated axon from Wallerian degeneration. The only way axon degeneration could be delayed was in the slow Wallerian degeneration (WIds) mouse. It will be interesting to identify the survival protein involved.

\section{The complexity of apoptotic signaling pathways: Restricted to mammals or already present in worms?}

So far execution of programmed cell death during the development of the nematode C.elegans has been viewed as a simple matter of two proteins, CED-3 and CED-4 that kill 
and a third, CED-9, that inhibits the killing. ${ }^{41}$ Another level of complexity has been added by the discovery of Egl-1 that binds to CED-9 and thereby releases and activates the CED3/CED-4 complex. ${ }^{42}$ M. Hengartner (Cold Spring Harbor, USA) continued the trend towards further complexities by showing that the regulation of natural cell death in germ cells and cell death induced by $\gamma$-irradiation involves additional molecules. While germ cells in the pachytene arrest state are resistant to cell death, they become sensitive to CED-4/CED3-mediated apoptosis when exiting this state. This cell death depends on an intact Ras/MAPK signaling pathway. By using EMS mutagenesis combined with acridine orange staining to detect dying cells, the group of $\mathrm{M}$. Hengartner found a gene called op152 whose mutation leads to excessive cell death in germ cells. Curiously, while a loss of function CED-3 mutant suppressed excessive death due to mutated op152, fertility was not restored indicating that the germ cells died anyway. Whether this type of cell death is necrotic or caspaseindependent has not yet been investigated. These data however indicate that op152 is probably a checkpoint gene product that decides whether an aberrant germ cell undergoes CED-3 mediated apoptosis or another type of cell death. Yet other gene products seem to be involved in apoptosis induced by DNA damaging agents. The Hengartner group identified rad-5 as a crucial mediator of $\gamma$-irradiation induced CED-3 activation and apoptosis. No implication of this gene product has yet been seen in natural programmed cell death of germ cells. Thus, several different pro- and anti-apoptotic factors seem to regulate various forms of caspase-dependent and probably caspase-independent cell deaths, a complexity that approaches that of mammalian apoptosis.

\section{Two additional milestones and concluding remarks}

In contrast to C.elegans, studying mammalian germ cell death has a long history. J. Tilly (Boston, USA) provided an impressive update of the molecular steps leading to ovarian cell death. One key element is pro-apoptotic Bax. Bax-null female mice fail to undergo the 'mouse equivalent' of the menopause due to the extra survival of germ cells that are normally lost by apoptosis in wild-type female mice. Moreover, Bax-deficient oocytes are resistant to apoptosis induced by chemotherapeutic agents such as doxorubicin. ${ }^{43}$ To determine the caspases involved, his group used caspase knock out mice to show that caspase-2 mediates and caspase-11 blocks female germ cell death. The survival effect of caspase11 is probably due to its IL- $1 \beta$ converting enzyme activity as caspase-11 knock out mice lack IL-1 $\beta$ production and IL-1 $\beta$ rescues primordial follicles from the death fate. As in C.elegans, two types of germ cell apoptosis are emerging in mammals, a naturally occurring and a damage-induced form. This is based on the finding that ovary-targeted Bcl-2 blocks cell death induced by doxorubicin but not that leading to menopause. Maybe Bcl-w, an anti-apoptotic Bcl-2 family member predominantly expressed in germ cells, is responsible for the interference with natural germ cell apoptosis.

Another unexpected complexity of apoptosis regulation has finally been introduced by $C$. Fankhauser (Zürich, Switzerland). He challenged the notion that the survival of developing neurons exclusively depends on a competition for survival factors such as NGF. His group discovered that the repulsive axon guidance cue semaphorin III (Sema III) actively induces cell body apoptosis of sensory neurons in the presence of NGF. This effect is specific for NGFdependent neurons as it is not seen with NT-3 dependent cells. Using GAP-43 knock out mice, he further shows that GAP-43, a protein implicated in axon guidance and nerve terminal sprouting, is necessary for Sema III-mediated neuronal killing. Thus, axon guidance and the control of cell survival/death seem to be linked processes.

With the discovery of more regulators of apoptosis, we realize that the death fate of a cell depends on the stimulus, the cell type and the context in which the cell is placed. A common theme is certainly the activation of caspases with the purpose to orderly degrade a cell and to prepare it for engulfment by neighbors. But cells may as well die without caspases and it will be crucial to find out how this works and how we can intervene with this type of cell death. Furthermore, it will be a major challenge to identify the sensor molecules that 'smell' apoptotic signals and can react respectively to launch the death program. Are these molecules part of commitment points or is commitment downstream of the sensor or not existing at all? These questions touch on the heart of the apoptotic machinery and will certainly keep us busy for a while!

\section{Acknowledgements}

The conference was supported by the Swiss Tissue Culture Society (STCS), the Swiss National Science Foundation, the Swiss Society for Experimental Biology, the Swiss Academy of Sciences, the University of Fribourg, Cosmital, Hoffmann-La Roche and Nestlé.

\section{References}

1. Ashkenazi A and Dixit VM (1998) Death receptors: signaling and modulation. Science 281: 1305-1308

2. Muzio M, Stockwell BR, Stennicke, HR, Salvesen, GS and Dixit VM (1998) An induced proximity model for caspase-8 activation. J. Biol. Chem. 273: 29262930

3. Thome M, Hofmann K, Burns K, Martinon F, Bodmer JL, Mattmann C and Tschopp J (1998) Identification of CARDIAK, a RIP-like kinase that associates with caspase-1. Curr. Biol. 8: 885-888

4. Yang X, Koshravi-Far R, Chang HY and Baltimore D (1997) Daxx, a novel Fasbinding protein that activates JNK and apoptosis. Cell 89: 1067-1076

5. Chang HY, Nishitoh H, Yang X, Ichijo H and Baltimore D (1998) Activation of apoptosis signal-regulating kinase 1 (ASK1) by the adapter protein Daxx. Science 281: $1860-1863$

6. Salvesen GS and Dixit VM (1997) Caspases: Intracellular signaling by proteolysis. Cell 91: $443-446$

7. Roy N, Deveraux QL, Takahashi R, Salvesen GS and Reed JC (1997) The c-IAP1 and C-IAP-2 proteins are direct inhibitors of specific caspases. EMBO J. 16: $6914-6925$

8. Takahashi R, Deveraux Q, Tamm I, Welsh K, Assa-Munt N, Salvesen GS and Reed JC (1998) A single BIR domain of XIAP sufficient for inhibiting caspases. J. Biol. Chem. 273: 7787-7790

9. Sakahira H, Enari M and Nagata S (1998) Cleavage of CAD inhibitor in CAD activation and DNA degradation during apoptosis. Nature 391: 96-99

10. Enari M, Sakahira H, Yokoyama H, Okawa K, Iwamatsu A and Nagata S (1998)A caspase-activated DNase that degrades DNA during apoptosis, and its inhibitor ICAD. Nature 391: 43-50 
11. Mao PL, Jiang Y, Wee BY and Porter AG (1998) Activation of caspase-1 in the nucleus requires nuclear translocation of pro-caspase-1 mediated by its prodomain. J. Biol. Chem. 273: 23621-23624

12. Scaffidi C, Fulda S, Srinivasan A, Friesen C, Li F, Tomaselli KJ, Debatin KM Krammer PH and Peter ME (1998) Two CD95 (APO-1/Fas) signaling pathways. EMBO J. 17: 1675-1687

13. Fulda S, Susin SA, Kroemer G and Debatin KM (1998) Molecular ordering of apoptosis induced by anticancer drugs in neuroblastoma cells. Cancer Res. 58: 4453-4460

14. Hueber AO, Zornig M, Lyon D, Suda T, Nagata S and Evan GI (1997) Requirement for the CD95 receptor-ligand pathway in c-Myc-induced apoptosis. Science 278: 1305-1309

15. Green DR and Reed JC (1998) Mitochondria and apoptosis. Science 281 1309-1312

16. Srinivasula SM, Ahmad M, Fernandes-Alnemri T and Alnemri ES (1998) Autoactivation of procaspase- 9 by Apaf-1-mediated oligomerization. Mol. Cell. 1: $949-957$

17. Hakem R, Hakem A, Duncan GS, Henderson JT, Woo M, Soengas MS, Elia A, de la Pompa JL, Kagi D, Khoo W, Potter J, Yoshida R, Kaufman SA, Lowe SW, Penninger JM and Mak TW (1998) Differential requirement for caspase 9 in apoptotic pathways in vivo. Cell 94: 339-352

18. Yoshida H, Kong YY, Yoshida R, Elia AJ, Hakem A, Hakem R, Penninger JM and Mak TW (1998) Apaf1 is required for mitochondrial pathways of apoptosis and brain development. Cell 94: 739-750

19. Li H, Zhu H, Xu CJ and Yuan J (1998) Cleavage of BID by caspase 8 mediates the mitochondrial damage in the Fas pathway of apoptosis. Cell 94: $491-501$

20. Luo X, Budihardjo I, Zou H, Slaughter C, Wang X (1998) Bid, a Bcl2 interacting protein, mediates cytochrome $c$ release from mitochondria in response to activation of cell surface death receptors. Cell 94: 481-490

21. Garcia-Ruiz C, Colell A, Mari M, Morales A and Fernandez-Checa JC (1997) Direct effect of ceramide on the mitochondrial electron transport chain leads to generation of reactive oxygen species. Role of mitochondrial glutathione. J. Biol. Chem. 272: 11369-11377

22. Richter C (1993) Pro-oxidants and mitochondrial $\mathrm{Ca}^{2+}$ : their relationship to apoptosis and oncogenesis. FEBS Lett. 325: 104-107

23. Zhang J, Alter N, Reed JC, Borner C, Obeid LM and Hannun YA (1996) Bcl-2 interrupts the ceramide-mediated pathway of cell death. Proc. Natl. Acad. Sci. USA. 93: $5325-5328$

24. Monney L, Olivier R, Otter I, Jansen B, Poirier GG and Borner C (1998) Role of an acidic compartment in tumor-necrosis-factor-alpha-induced production of ceramide, activation of caspase-3 and apoptosis. Eur. J. Biochem. 251: $295-$ 303

25. Hockenbery DM, Oltvai ZN, Yin XM, Milliman CL and Korsmeyer SJ (1993) Bcl-2 functions in an antioxidant pathway to prevent apoptosis. Cell 75: 241-251

26. Kane DJ, Sarafian TA, Anton R, Hahn H, Gralla EB, Valentine JS, Ord T and Bredesen DE (1993) Bcl-2 inhibition of neural death: decreased generation of reactive oxygen species. Science 262: $1274-1277$

27. Hu Y, Benedict MA, Wu D, Inohara N and Nunez G (1998) Bcl-XL interacts with Apaf-1 and inhibits Apaf-1-dependent caspase-9. Proc. Natl. Acad. Sci. USA. 95: 4386-4391

28. Pan G, O'Rourke K and Dixit VM (1998) Caspase-9, Bcl-XL, and Apaf-1 form a ternary complex. J. Biol. Chem. 273: 5841-5845
29. Krajewski S, Tanaka S, Takayama S, Schibler MJ, Fenton W and Reed JC (1993) Investigation of the subcellular distribution of the bcl-2 oncoprotein: residence in the nuclear envelope, endoplasmic reticulum, and outer mitochondrial membranes. Cancer Res. 53: 4701-4714

30. Han J, Wallen HD, Nunez G and White E (1998) E1B 19,000-molecular-weight protein interacts with and inhibits CED-4-dependent, FLICE-mediated apoptosis. Mol. Cell. Biol. 18: 6052-6062

31. Bergeron JJ, Brenner MB, Thomas DY and Williams DB (1994) Calnexin: a membrane-bound chaperone of the endoplasmic reticulum. Trends. Biochem. Sci. 19: $124-128$

32. Tirasophon W, Welihinda AA and Kaufman RJ (1998)A stress response pathway from the endoplasmic reticulum to the nucleus requires a novel bifunctional protein kinase/endoribonuclease (Ire1p) in mammalian cells. Genes Dev. 12: $1812-1824$

33. Metzstein MM, Hengartner MO, Tsung N, Ellis RE and Horvitz HR (1996) Transcriptional regulator of programmed cell death encoded by Caenorhabditis elegans gene ces-2. Nature 382: $541-544$

34. InabaT, Inukai T, Yoshihara T, Seyschab H, Ashmun RA, Canman CE, Laken SJ, Kastan MB and Look AT (1996) Reversal of apoptosis by the leukaemiaassociated E2A-HLF chimaeric transcription factor. Nature 382: 545-547

35. Rossé T, OlivierR, Monney L, Rager M, Conus S, Fellay I, Jansen B and Borner C (1998) Bcl-2 prolongs cell survival after Bax-induced release of cytochrome c. Nature 391: $496-499$

36. Grandgirard D, Studer E, Monney L, Belser T, Fellay I, Borner C and Michel MR (1998) Alphaviruses induce apoptosis in Bcl-2-overexpressing cells: evidence for a caspase-mediated, proteolytic inactivation of Bcl-2. EMBO J. 17: 12681278

37. Jansen B, Schlagbauer-Wadl H, Brown BD, Bryan RN, van Elsas A, Muller M, Wolff K, Eichler HG and Pehamberger H (1998) Bcl-2 antisense therapy chemosensitizes human melanoma in SCID mice. Nat. Med. 4: 232-234

38. Adams JM and Cory S (1998) The Bcl-2 protein family: arbiters of cell survival. Science 281: $1322-1326$

39. Olie RA, Durrieu F, Cornillon S, Loughran G, Gross J, Earnshaw WC and Golstein P (1998) Apparent caspase independence of programmed cell death in Dictyostelium. Curr. Biol. 8: 955-958

40. Weil M, Jacobson MD and Raff MC (1998) Are caspases involved in the death of cells with a transcriptionally inactive nucleus? Sperm and chicken erythrocytes. J. Cell Sci. 111: 2707-2715

41. Hengartner MO and Horvitz HR (1994) Programmed cell death in Caenorhabditis elegans. Curr. Opin. Genet. Dev. 4: 581-586

42. Conradt B and Horvitz HR (1998) The C. elegans protein EGL-1 is required for programmed cell death and interacts with the Bcl-2-like protein CED-9. Cell 93: 519-529

43. Perez GI, Knudson CM, Leykin L, Korsmeyer SJ and Tilly JL (1997) Apoptosisassociated signaling pathways are required for chemotherapy-mediated female germ cell destruction. Nat. Med. 3: 1228-1232

44. Eskes R, Antonsson B, Osen-Sand A, Montessuit S, Richter C, Sadoul R, Mazzei G, Nichols A and Martinou JC (1998) Bax-induced cytochrome c release from mitochondria is independent of the permeability transition pore but highly dependent on $\mathrm{Mg}^{2+}$ Ions. J Cell Biol 143: 217-224

45. Torgler CN, de Tiani M, Raven T, Aubry JP, Brown R and Meldrum E (1997) Expression of bak in $\mathrm{S}$. pombe results in a lethality mediated through interaction with the calnexin homologue Cnx1. Cell Death Differ 4: 263-271 